\section{BMJ Open}

Ophthalmology

\title{
Predictors for diabetic retinopathy progression-findings from nominal group technique and Evidence review
}

\author{
Sajjad Haider (D) , ${ }^{1}$ Salman Naveed Sadiq, ${ }^{2}$ Eniya Lufumpa, ${ }^{1}$ Harpreet Sihre, ${ }^{1}$ \\ Mohammad Tallouzi, ${ }^{1}$ David J Moore, ${ }^{3}$ Krishnarajah Nirantharakumar, ${ }^{3}$ \\ Malcolm James Price ${ }^{3}$
}

To cite: Haider S, Sadiq SN Lufumpa E, et al. Predictors for diabetic retinopathy progression-findings from nominal group technique and Evidence review. BMJ Open Ophthalmology 2020;5:e000579. doi:10.1136/ bmjophth-2020-000579

- Additional material is published online only. To view, please visit the journal online (http://dx.doi.org/10.1136/ bmjophth-2020-000579).

DJM, KN and MJP are joint senior authors.

Received 15 July 2020 Revised 15 August 2020 Accepted 17 August 2020
Check for updates

(c) Author(s) (or their employer(s)) 2020. Re-use permitted under CC BY. Published by BMJ.

${ }^{1}$ University of Birmingham, Birmingham, UK

${ }^{2}$ Ophthalmology, Royal Victoria Infirmary, Newcastle, UK ${ }^{3}$ Institute of Applied Health Research, University of Birmingham, Birmingham, UK

Correspondence to Dr Sajjad Haider; SXH397@ student.bham.ac.uk

\section{ABSTRACT}

Objectives Risk stratification is needed for patients referred to hospital eyeservices by Diabetic Eye Screening Programme UK. This requires a set of candidate predictors. The literature contains a large number of predictors. The objective of this research was to arrive at a small set of clinically important predictors for the outcome of the progression of diabetic retinopathy (DR). They need to be evidence based and readily available during the clinical consultation.

Methods and analysis Initial list of predictors was obtained from a systematic review of prediction models. We sought the clinical expert opinion using a formal qualitative study design. A series of nominal group technique meetings to shorten the list and to rank the predictors for importance by voting were held with National Health Service hospital-based clinicians involved in caring for patients with DR in the UK. We then evaluated the evidence base for the selected predictors by critically appraising the evidence.

Results The source list was presented at nominal group meetings $(n=4)$, attended by 44 clinicians. Twenty-five predictors from the original list were ranked as important predictors and eight new predictors were proposed. Two additional predictors were retained after evidence check. Of these 35,21 had robust supporting evidence in the literature condensed into a set of 19 predictors by categorising DR.

Conclusion We identified a set of 19 clinically meaningful predictors of DR progression that can help stratify higher-risk patients referred to hospital eye services and should be considered in the development of an individual risk stratification model.

Study design A qualitative study and evidence review. Setting Secondary eye care centres in North East, Midlands and South of England.

\section{INTRODUCTION}

Diabetic retinopathy (DR) can develop in anyone with diabetes mellitus (DM) and is a major cause of blindness due to damage to, and disruption of the retina (the light-sensitive layer at the back of the eye) leading to loss of sight. DR is a consequence of changes to the blood vessels in this part of the eye leading to

\section{Key messages}

What is already known about this subject?

- A large list of already identified predictors, for diabetic retinopathy progression was available but had duplications and overlap.

\section{What are the new findings?}

- With the clinical experts' opinion using nominal group technique and evidence evaluation we identified a shorter, evidence-based and pragmatic list of 19 predictors, which was also ranked by clinical importance.

\section{How might these results change the focus of research or clinical practice?}

- This set of candidate predictors can help stratify patients with referable diabetic retinopathy under hospital ophthalmology services through risk stratification.

leakage of blood and fluid and the formation of abnormal blood vessels. ${ }^{1}$

There has been a global increase in the number of adults with DM from an estimated 108 million in 1980 to 422 million in $2014 .^{2}$ The rise in diabetes prevalence coupled with early detection of DR through better population eye screening coverage has increased the burden of patients with DR to healthcare systems. ${ }^{3}$

In the UK, DR services are organised into the Diabetic Eye Screening Programme (DESP) for lower-risk patients and the hospital eye services (HES) for higher-risk patients with referable DR, with the HES providing treatment, and closer observation of patients. While services may be organised differently in other countries, the care pathways are likely to be similar for these patients. Patients with DR are referred to the HES when they develop clinical signs of the so called sight-threatening retinopathy. The clinical signs based on photographs are the only differentiating features used for this risk stratification. However, approximately $50 \%-70 \%$ of referrals ${ }^{45}$ do not need intervention and are observed in 
the HES for varying periods of time. This is one reason for a demand and capacity mismatch in HES.

There have been successful attempts to optimise the diabetic screening services through risk stratification of patients with the help of a prognostic prediction model. ${ }^{6} \mathrm{~A}$ similar approach could be used to improve safety and efficiency of DR services in the hospital environment. However, a recent systematic review of prediction models for DR found that none of the 14 models identified were directly applicable for the higher-risk patients in the hospital setting. ${ }^{7}$

Predictors ${ }^{8}$ are at the core of prevention and prediction of a clinical event. Predictors could be, for example, an individual attribute, a clinical feature, a physiological, psychosocial or an environmental factor. Predictor research ranges from 'exploration' to 'confirmation' to 'replication'. Exploration refers to a predictor being mentioned in a primary study as a risk factor for being part of the causal pathway. Confirmation is established if a predictor retains prognostic value even after adjustment for other predictors. Replication is the assessment of the predictor in multiple independent studies. Publication and reporting biases are common in predictors' research. $^{9}$

A prediction model combines two or more predictors (also called prognostic factors) to predict the likelihood of an outcome, for example, DR progression to a treatment requiring stage or loss of vision, before it occurs. ${ }^{10}$ Previous prediction models in the systematic review ${ }^{7}$ have between them used 78 different candidate predictors. However, there are problems with the direct use of these predictors for the HES setting. First, a set of predictors this large is not feasible for use in clinical practice. Second, many of these predictors have not been confirmed. Third, a number of predictors were extrapolated from evidence for macrovascular outcomes like stroke to retinopathy progression inappropriately, for example, 'smoking' and 'ethnicity'. ${ }^{11}$ Fourth, there was significant duplication and overlap between the predictors, for example, diabetic nephropathy and chronic kidney disease. Such highly correlated predictors are unlikely to be independently predictive in the same model. ${ }^{7}$ Finally, there may be predictors for higher-risk patients, not reported in the prediction model studies as they were primarily for lowrisk patients.

There were two comprehensive and up to date evidence reviews on the subject of predictors. However, their perspective was quite different from ours. They were a rich resource of evidence and very useful for horizon scanning, ${ }^{1213}$ but most of the predictors they suggested are still in research domain and not being recorded in the patient notes, so not possible

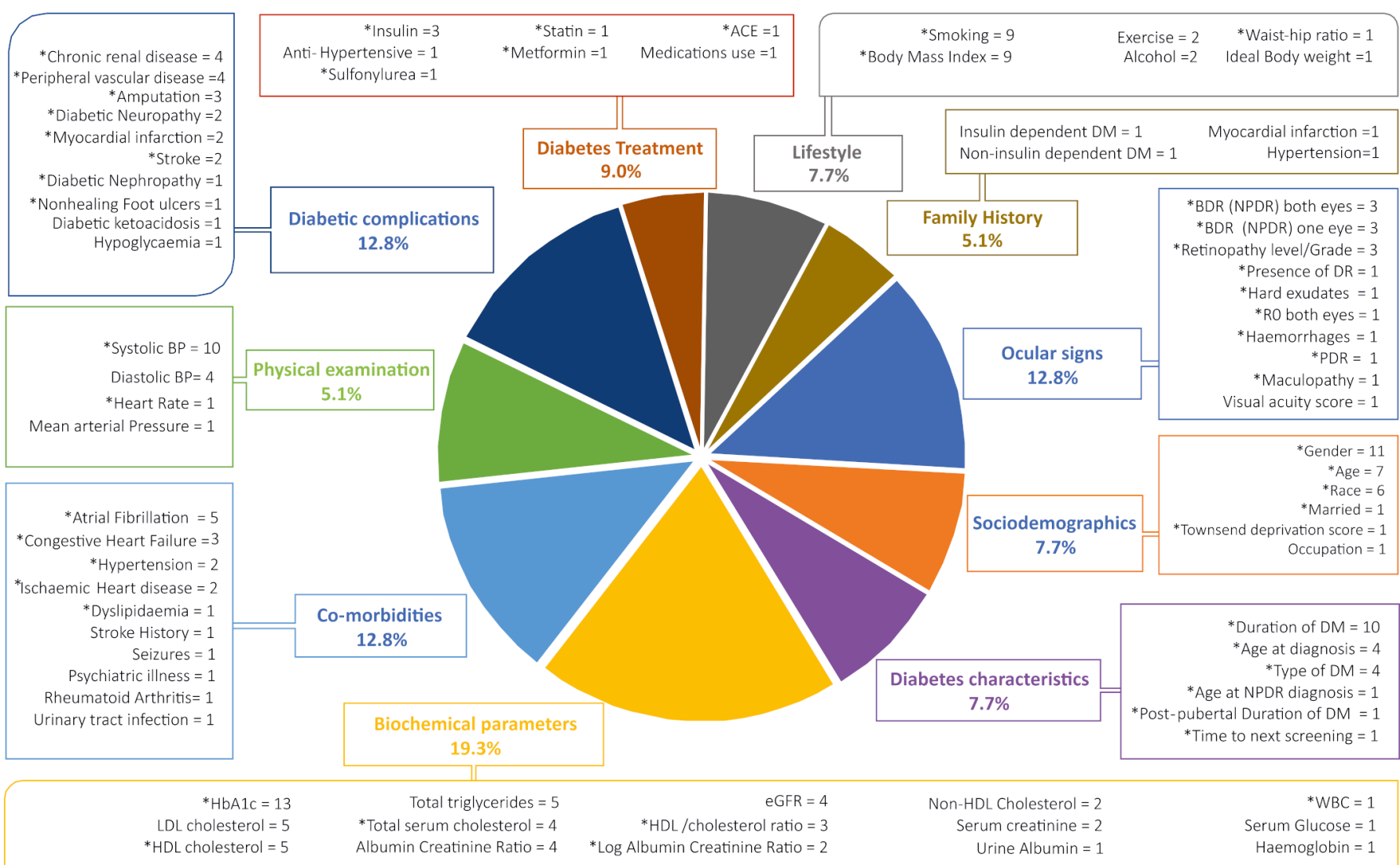

Figure 1 List of candidate predictors from systematic review model development studies. Pie chart illustrates the percentage proportion of each category of predictors. Boxes indicate the type of candidate predictors in each category along with the number of modelling studies that considered them. Information on the full list of candidate predictors is given in online supplemental appendix A3. ${ }^{*}$ The predictor was used in at least one model development. eGFR, estimated glomerular filtration rate; HbA1c, glycated haemoglobin; HDL, High Density Lipoproteins; LDL, Low Density Lipoproteins; WBC, White Blood Cells; BDR, Background Diabetic Retinopathy; NPDR, Non Proliferative Diabetic Retinopathy; PDR, Proliferative Diabetic Retinopathy. 


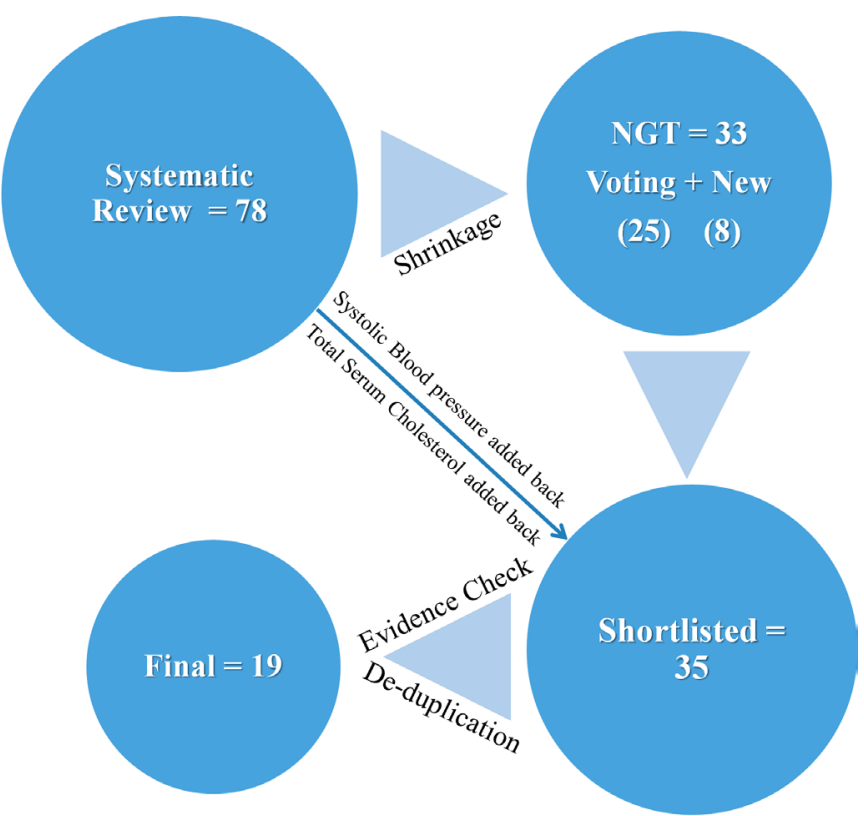

Figure 2 Summary of the sequence involved in reaching the final list of candidate predictors in table 3. NGT, nominal group technique.

at the moment to be used within prognostic research. We instead used the modelling studies included within the systematic review assuming most of them will be evidence based and for the practical reason that they will have been measured and thus can be extracted from the data.

\section{Aims}

In this qualitative study, we aimed to deduplicate the list of predictors and through clinicians input and evidence assessment to arrive at a shorter list, more clinically relevant to high-risk patients.

\section{Objectives}

1. To identify all the predictors for DR progression in the literature

2. To seek clinicians' opinion about the most important predictors among them for high-risk patients and to identify any new predictors not yet described.

3. To assess the evidence base from published literature for each predictor identified in objective 2 .

4. To finalise a potentially parsimonious set, that is, a minimal number of predictors in a future multivariate model able to give the highest predictive performance. ${ }^{1415}$

\section{METHODS}

\section{Study design and methods}

Our recent systematic review of prognostic modelling studies for the development of DR of any type including maculopathy in patients with diabetes ${ }^{7}$ was the primary source of a list of candidate predictors. The text and the reference lists of the modelling studies were searched for the candidate predictors. A qualitative study design (Delphi) has been used with the aim to prioritise the list of already identified predictors. ${ }^{16}$
Table 1 List of predictors chosen by NGT by number of votes and voting frequency

\begin{tabular}{|c|c|c|c|}
\hline \multicolumn{2}{|c|}{ Predictor } & \multirow{2}{*}{$\begin{array}{l}\begin{array}{l}\text { Voting } \\
\text { frequency }\end{array} \\
31\end{array}$} & \multirow{2}{*}{$\begin{array}{l}\begin{array}{l}\text { Proportion } \\
\text { voted (total } \\
\mathrm{n}=44)(\%)^{*}\end{array} \\
70\end{array}$} \\
\hline 1 & $\mathrm{HbA1c}$ & & \\
\hline 2 & Duration of diabetes & 24 & 55 \\
\hline 3 & Retinopathy level & 17 & 39 \\
\hline 4 & Townsend score & 16 & 36 \\
\hline 5 & Smoking (lifestyle) & 12 & 27 \\
\hline 6 & Race & 11 & 25 \\
\hline 7 & Proliferative DR & 11 & 25 \\
\hline 8 & DNA† & 10 & 23 \\
\hline 9 & Nephropathy & 9 & 20 \\
\hline 10 & Hypertension & 9 & 20 \\
\hline 11 & Maculopathy & 8 & 18 \\
\hline 12 & Pregnancy† & 7 & 16 \\
\hline 13 & Comorbidities $†$ & 7 & 16 \\
\hline 14 & Exercise/physical activity & 6 & 14 \\
\hline 15 & Type of DM & 5 & 11 \\
\hline 16 & BMl & 5 & 11 \\
\hline 17 & eGFR & 4 & 9 \\
\hline 18 & Chronic renal disease & 4 & 9 \\
\hline 19 & $\begin{array}{l}\text { Rapid reduction of blood } \\
\text { sugar (early worsening) } \dagger\end{array}$ & 4 & 9 \\
\hline 20 & Dyslipidaemia & 3 & 7 \\
\hline 21 & Psychiatric illness & 3 & 7 \\
\hline 22 & Visual acuity score & 2 & 5 \\
\hline 23 & DBP & 2 & 5 \\
\hline 24 & Only eye† & 2 & 5 \\
\hline 25 & Age at diagnosis & 1 & 2 \\
\hline 26 & Chronic infection† & 1 & 2 \\
\hline 27 & Preproliferative† & 1 & 2 \\
\hline 28 & Neuropathy & 1 & 2 \\
\hline 29 & Age & 1 & 2 \\
\hline 30 & Statins & 1 & 2 \\
\hline 31 & Insulin & 1 & 2 \\
\hline 32 & Gender & 1 & 2 \\
\hline 33 & Diet† & 1 & 2 \\
\hline
\end{tabular}

*Voting frequency in percentages arranged in order of high to low. NGT selected 25 out of 78 candidate predictors list. †Eight new predictors were added by NGT for a total of 33 predictors.

$\mathrm{BMI}$, body mass index; DBP, diastolic blood pressure; $\mathrm{DM}$, diabetes mellitus; DNA, did not attend; DR, diabetic retinopathy; eGFR, estimated glomerular filtration rate; $\mathrm{HbA1c}$, glycated haemoglobin; NGT, nominal group technique.

Techniques other than nominal group technique (NGT) such as brainstorming, focus group and Delphi methods were considered ${ }^{17}$ along with their technical strengths and 
limitations. NGT was used to shrink the list of candidate predictors. Primary studies were then evaluated for evidence. In case no reference of the primary study was found in the modelling study, searches were made in Pubmed and Scopus. Subsequently, the evidence behind the shortlisted predictors was evaluated using the Quality in Prognosis Studies (QUIP) tool. ${ }^{18}$ To comply with the PROGRESS (Prognosis research strategy) framework for predictors, ${ }^{9}$ we used a criterion of at least 'exploration' (exploring predictor's relation to prognosis) within primary studies before including them into the list of our candidate predictors for future models, to ensure that the risk of the outcomes of interest can be calculated more precisely by using those predictors by a future model. ${ }^{10}$

\section{Nominal group technique}

NGT is a qualitative research methodology, where every meeting is a structured small group exercise allowing judgements by individuals to be pooled to arrive at a decision in an uncertain situation. ${ }^{1719}$ NGT has been used frequently in ophthalmology and medicine ${ }^{20-28}$ and is a highly adaptable method. ${ }^{29}$

An information pack with the predictors list from the systematic review was sent to participating unit before the meeting ${ }^{7}$ (online supplemental appendices A1-A4). Informed consent forms were provided and signed by participants (online supplemental appendix A2). NGT was performed through a series of four meetings, each lasting around 1.5 hours. Meetings were accommodated within clinical governance/audit meetings of four National Health Service (NHS) trusts with the permission of respective research and development directorates. NGT was chosen, because of its modifiable nature allowing brainstorming to decide on importance of predictors, a round-robin for an equal opportunity for all participants, a discussion for clarifications, voting for final decision on ranking and for being time efficient. Each meeting was conducted in four stages (online supplemental appendix A4): from providing background information, round-robin recording of ideas, discussion of the list of ideas and ending in voting for ranking of the ideas generated.

During the round-robin recording, the facilitator went around the table inviting one item from each participant at a time (to give equal opportunity to all the participants) and recording them on the flip chart. It was left open to participants to choose any number of predictors from the list provided or name their own predictors using their personal experience and insight. We requested participants to restrict their final choices to a total of 15-20 predictors.

The round-robin cycles (within a meeting and between the meetings) were repeated until saturation had been achieved-a point where no new predictors were being added and thus all new information had been obtained. ${ }^{30} 31$ The centres were recruited sequentially and from the second meeting onward, after every meeting cumulative results were examined for any new predictors suggested and thus monitoring for saturation (when no further predictors were being added) before stopping to recruit.

\section{Participants}

To ensure a maximum range of views and opinions were collected, keeping purposeful sampling in mind that is, selection of information-rich resource for the research question ${ }^{32}$ as a priority, we approached medical retina team leaders for four NHS trusts (consultants with much longer training and experience) $)^{33}$ with their teams of middle grades and registrars, nurses and optometrists, directly involved in caring for patients with DR, for these meetings. We aimed to over-recruit allowing for likely no-shows/ dropouts on the day for each group.

\section{Data collection}

Reflexivity $^{34}$ of the authors was considered when designing the project. $\mathrm{SH}$ is an ophthalmologist and thus shared the participants' experience. He moderated the meetings, but one or more of the qualitative study researchers (HS, EL or MT) were also present to reduce the chances of bias. Clinicians were asked for their written consent (online supplemental appendix A2) for information collected to be used for further research and publication. Flip chart and marked lists were collected at the end of discussion while voting and all other information was collated on a spreadsheet. All participant data were anonymised, with no direct quotes mentioned in any dissemination.

Data extraction in spreadsheet and collation after every meeting were carried out by one of the coauthors involved in that meeting and validated with the paper forms with the help of a second researcher. We collated all new predictors suggested by clinical colleagues participating in these meetings, added them to the list provided and helped participants rank them for importance in prognosis prediction.

\section{Analyses of NGT}

Voting frequency was calculated for voting scores per predictor (summing of scores) as well as frequency of voting percentage (score achieved for the item/maximum possible score $\times 100)$ and tabulated according to their rank. ${ }^{29}$

\section{Evidence review}

In this step, we searched the reference lists of the modelling studies identified in the systematic review ${ }^{7}$ for primary studies that had investigated the predictors selected by NGT and subjected them to critical appraisal using the QUIP tool. ${ }^{18} \mathrm{~A}$ basic literature search was then performed in Pubmed and Scopus to identify primary studies for predictors where no primary evidence source was referenced in any modelling study. Using the identified information, we summarised the status of each predictor as explored, confirmed or confirmed and replicated in more than one study.

\section{Patients and public involvement}

While there was no direct patients and public involvement required in this research, we included all the predictors from Individualised Screening for Diabetic Retinopathy 
(ISDR) model which were chosen by an expert patient panel $^{35}$ to reflect patient input.

\section{Ethics}

The protocol was evaluated by the four NHS trusts where the NGT was carried out. Since the research was essentially a decision exercise based on clinicians' expert opinion and did not involve patient data, no ethical approval was required.

\section{RESULTS}

The list of 78 candidate predictors from the systematic review are given in figure 1 (shows their breakdown and frequency of their use in the pool of 14 models) and in Appendix A3. ${ }^{7}$ Biochemical predictors were used most commonly. Figure 2 shows the predictor items flow during the processes of NGT and evidence evaluation.

\section{Nominal group technique}

We conducted four NGT meetings, within secondary care eye centres in NHS trusts in the following areas in the UK: $(1,2)$ Two Midland trusts, (3) North East England and (4) South of England. After the fourth NGT meeting, saturation was reached. The full set of 33 predictors selected by the clinicians are shown in table 1. Participants' roles varied from consultants, specialist registrars, middle-grade doctors and allied health professionals (one optometrist and one nurse). A total of 44 clinicians participated with numbers per session ranging from 6 to 16 (online supplemental appendix A4). Eleven out of 19 participating consultants were medical retina trained. After multiple round-robin cycles (within a meeting and different meetings) had been repeated to ensure saturation had been achieved and no new predictors were being added (online supplemental appendix A6), the final set of candidate predictors as decided by NGT is given in table 1.

\section{Evidence evaluation}

Following NGT, during the evidence review, two further predictors from the original list of 78 were added back to give a total of 35 predictors (table 2). 'Systolic blood pressure' (SBP) was included because of the participation of patient expert panel in ISDR model, ${ }^{35}$ was the third the most common predictor used in prognostic models and has a good evidence base. The NGT participants probably implicitly included it by selecting hypertension as well. Total serum cholesterol was added back as a proxy for dyslipidaemia as difficulties with reporting of this predictor have previously been reported. ${ }^{36}$

After NGT, residual duplication/overlap still remained, for example, 'diabetic nephropathy' and 'chronic kidney disease', 'hypertension', 'diastolic blood pressure' (DBP) and 'SBP', 'dyslipidaemia', 'cholesterol' and 'statins'. 'Diabetic nephropathy' is the primary cause of 'chronic kidney disease' characterised by progressive decline of ${ }^{37}$ 'estimated glomerular filtration rate' (eGFR). Therefore 'eGFR' was retained in preference to 'chronic kidney disease' and 'diabetic nephropathy' as it is established as a predictor for DR and is more sensitive than the earlier two predictors. ${ }^{38}$ In the case of the overlap between 'hypertension', 'DBP' and 'SBP', the latter two predictors are represented in 'hypertension' but seem to have different prognostic values, so were retained. ${ }^{39} 40$

We did not find any primary studies supporting the association between DR progression and 'psychiatric illness' or 'diabetic neuropathy'. Among the studies found, no proven association of DR with 'BMI', ${ }^{41}$ 'exercise/physical activity" ${ }^{42}$ or 'smoking ${ }^{43}{ }^{44}$ was seen but a weak association was seen with 'serum cholesterol'. The last item was therefore retained, and the rest excluded.

Among the new predictors suggested by NGT, primary studies were found confirming the association for 'early worsening', 'pregnancy', ${ }^{45}$ frequent 'DNA', ${ }^{47}$ and 'preproliferative DR'. ${ }^{48}$ Due to the lack of evidence, the remaining four predictors ('comorbidities', 'only eye situation', 'Diet" and 'chronic infection') were excluded.

The most common primary studies quoted were UKPDS, ${ }^{39} 404348-50$ Diabetes Control and Complications Trial (DCCT) ${ }^{45}{ }^{51}{ }^{52}$ Wisconsin Epidemiological Study of Diabetic Retinopathy, ${ }^{53}{ }^{54}$ Epidemiology and Prevention of Diabetes Study (EURODIAB) $)^{55}$ and Action to control cardiovascular risk in diabetes (ACCORD) ${ }^{56}$ Table 2 tabulates primary studies and status of confirmation and replication for individual predictors. Fourteen predictors were excluded for reasons of no proven association, duplication/overlap. The remaining 21 predictors were condensed into 19 predictors (table 3 ) by combining the DR categories together.

Only 2 out of 14 modelling studies ${ }^{425}$ reported primary studies for all of the prognostic factors/predictors used. One of the modelling studies used the items without giving reference to any primary study ${ }^{35}$ but instead quoted literature review/expert patients' panel. A model partly relied on borrowing the items from other models, ${ }^{42}$ some could be traced from the reference list but were not in context. ${ }^{42} 58$ It was not clear in $8(23 \%)$ out of 35 predictors, as to which primary studies confirmed them (given in table 2).

Most of the primary studies had multiple publications. Out of 35 predictors, $25(71 \%)$ had good supporting evidence of predictive value from the literature (table 2). Four predictors were excluded because of overlap/duplication. Out of 18 primary studies critically appraised in online supplemental appendix A7, the evidence base for only one primary study had a high risk of bias, mainly due to confounders issues and highly selective population. ${ }^{59}$ The factor involved did have another supporting study with low risk of bias. Three predictor studies were judged to have moderate risk of bias and 15 predictor studies were low risk of bias (79\% of primary predictors studies) on QUIP criteria.

\section{DISCUSSION}

\section{Statement of principal findings}

We used clinical opinion in the NGT meetings to reduce a list of 78 previous candidate predictors to a list of 25 potential predictors. The study also suggested a further 
Table 2 Predictors and their primary studies with confirmation and replication status

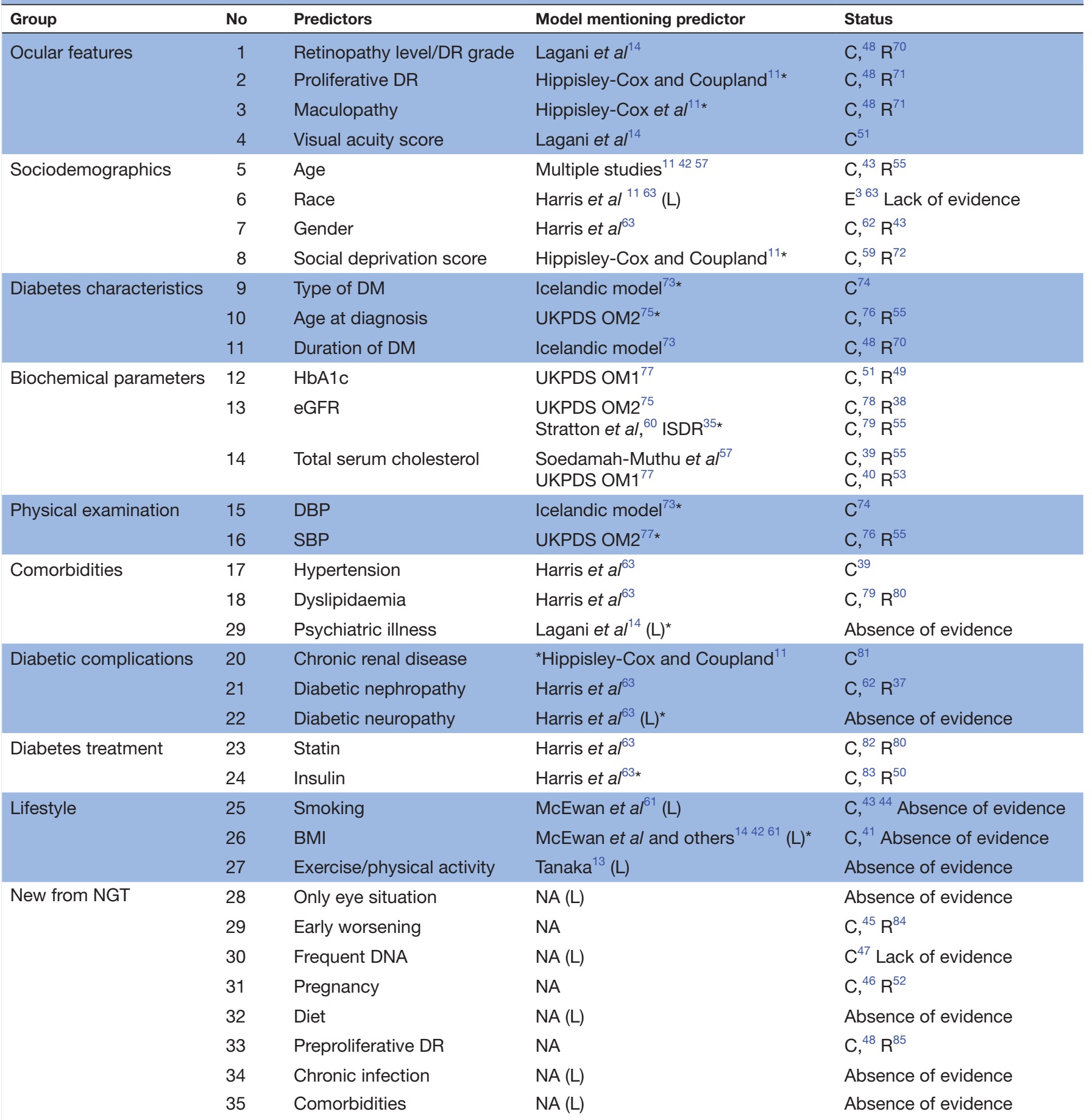

*Modelling study did not clearly identify the primary study for the predictor. Details in text.

BMI, body mass index; C, confirmation; DBP, diastolic blood pressure; DM, diabetes mellitus; DNA, did not attend; DR, diabetic retinopathy; E, exploration; eGFR, estimated glomerular filtration rate; HbA1c, glycated haemoglobin; ISDR, Individualised Screening for Diabetic Retinopathy; L, lacking evidence; NA, not applicable; R, replication; SBP, systolic blood pressure ; UKPDS, United Kingdom prospective Diabetes Study.

eight potential predictors (table 1). After evidence review, we added back another two predictors.

The new predictors suggested by the NGT made good clinical/biological sense, but four of them ('Comorbidities', 'only eye situation', 'diet', 'chronic infections') have not been explored for association with DR progression, although it is possible that the last two may be operational through other variables such as glycated haemoglobin (HbA1c) rise due to uncontrolled blood sugar. The 'only eye' situation clearly has a higher risk of blindness because of the absence of function in the affected eye, or higher risk because of the same pathology as the 


\begin{tabular}{lll}
\hline \multicolumn{2}{l}{ Table 3} & Final list of candidate predictors \\
\hline \multicolumn{1}{l}{ Group } & Ocular features & Predictors \\
\hline 1 & & Presence and DR grade \\
& & b. Proliferative DR \\
& & C. Maculopathy \\
2 & & Visual acuity score \\
\hline 3 & Sociodemographic & Age at STR diagnosis \\
4 & & Age \\
5 & & Race \\
6 & & Gender \\
7 & & Social deprivation score \\
\hline 8 & Diabetes characteristics & Type of DM \\
9 & & Duration of DM $>10$ years \\
\hline 10 & Biochemical parameters & HbA1c \\
11 & & eGFR \\
12 & & Total serum cholesterol \\
13 & Physical examination & SBP \\
14 & & DBP \\
\hline 15 & Diabetes treatment & Statin \\
16 & & Insulin \\
\hline 17 & NGT* & Pregnancy \\
\hline 19 & & Early worsening \\
\hline
\end{tabular}

*Preproliferative DR, new from NGT is moved up to appear with the rest of DR categories, 4 condensed into 1, and thus 21 predictors condensed into 19. Also 'age at diagnosis' was specified to 'age at STR diagnosis' to conform with our target population of referable DR.

DBP, diastolic blood pressure; DM, diabetes mellitus; DR, diabetic retinopathy; eGFR, estimated glomerular filtration rate; HbA1c, glycated haemoglobin; NGT, nominal group technique; SBP, systolic blood pressure; STR, sightthreatening retinopathy.

lost eye but has not been investigated for its association with DR progression. The other three predictors, 'early worsening', 'pregnancy' and 'preproliferative DR' have a proven association with our outcome of interest and were therefore included. While specific comorbidities were considered as mentioned above, 'comorbidities' presence or numbers as a predictor had no supporting evidence. 'Frequent DNA' has been proven to add prognostic value, so has been added to the final list but is in need for further confirmation.

The top three ranked predictors from NGT (HbAlc, duration of diabetes and DR grade) were the same as the low risk of bias models' predictor sets (online supplemental appendix A7) chosen by the systematic review. ${ }^{7}$ This was in spite of this information being withheld from the participants in the NGT meetings. This shows the clinicians' intuitive thinking matches the findings of the systematic review as well. The approach of using retinopathy stages data alone to develop a risk stratification tool in DESP environment has been suggested.$^{60}$ ISDR model $^{35}$ in complete contrast has suggested using clinical predictors alone, especially for higher-risk patients. We looked at risk estimates of the various predictors within various models. They tend to vary depending on the combination of predictors used. ${ }^{6}{ }^{14}$ However, ocular predictors generally showed higher relative risk estimates. We suggest that any future model should contain a combination of ocular and systemic predictors for use in higher risk hospital population, as the values of, for example, SBP and HbAlc and so on are likely to be higher and can thus add significantly to the predictive ability. A practical sized set is now available, with individual predictors ranked in importance as perceived by the NGT participants. A prediction model for higher-risk DR could be built based on them in appropriate population data.

Several predictors in previously reported models were associated with diabetic complications other than retinopathy-in multiple outcomes or composite outcome models. ${ }^{1457}$ The evidence for association of some of these predictors with DR is unclear. For example, DR was a main covariate for severity of 'diabetic polyneuropathy', ${ }^{14} 39$ but it still remains to be seen if the reverse is also true. 'Smoking' as a candidate predictor was included in the majority of the models but made it to the final set only in one of them. ${ }^{61}$ The primary studies failed to show it as a predictor for DR progression. ${ }^{432}$ Harris $e t a l^{63}$ included ethnicity in their final model but HR p value crossed the recommended threshold of $>0.2$, so was of doubtful statistical significance. It was included in five models as candidate predictor but not made to any of the final set on statistical testing. However, there is indirect evidence of higher risk of south Asians to develop $\mathrm{STR}^{3}$ and blacks and South Asians among patients under DESP having a higher prevalence of visual impairment. ${ }^{64}$ We therefore included ethnicity in the final set.

\section{Strengths and weaknesses of the study}

We based this study on the full list of predictors that had duplication, overlap and extrapolation of evidence from outcomes other than DR progression. In this situation with a large number of predictors already confirmed and replicated, incorporating clinical insight through a qualitative study design was invaluable to reach a shorter, more manageable list and also generate some new predictors. This is also the first study to evaluate the evidence base of potential predictors used in existing prognostic models for DR progression and to follow the Prognosis Research strategy (PROGRESS) framework recommendations. ${ }^{9} \mathrm{We}$ noted reporting deficiencies and have suggested possible preventive strategies for future.

\section{Strengths and weaknesses in relation to other studies}

The ISDR model ${ }^{35}$ mentioned using a patient expert panel for decision-making during the predictor selection process. There is not enough detail in the study design, and we assume that it is only comparable to our work in that the study design was a qualitative one. We provide 
here the details of our methods and results with the interpretation. Our list also includes all the ISDR predictors, reflecting their expert patients' input. The Standardisation of Uveitis Nomenclature ${ }^{20}$ and Consensus on Outcome Measures for Glaucoma Effectiveness Trials ${ }^{25}$ are prime examples of successful use of NGT to arrive at a decision with the help of expert panels in ophthalmology. Another qualitative study looked into the patientperceived risks of disease and benefits of treatment $t^{65}$ but did not address predictors selection. We wanted to build on this approach seeking clinical experts' opinion with the help of NGT meetings.

\section{Implications for clinicians and policymakers}

This set of predictors derived will be useful to risk stratify patients, optimise treatment strategies, inform patients about their personal risks and improve research strategies as well as providing the building blocks for future prognostic models. ${ }^{9}$ A set of predictors based on these 19 finalised predictors could be used to risk stratify the population received within the HES after referral from DESP, to help with prioritisation of appointments and thus direct the resources more appropriately. Alternatively, a model could be constructed to estimate an individual patient's risk. This research will help the clinicians manage their patients according to their risk of progression.

While we have attempted to develop a list of predictors that are useful in predicting patients who progress from referable DR to a stage of needing treatment or vision loss, the list is primarily from patients with diabetes under screening for incident DR and referable DR and as such are generalizable as markers for progression to any stages.

\section{Unanswered questions and future research}

Risk of bias assessment did not affect our decision to exclude any predictors as vast majority of the predictors had good evidence base. PROGRESS criteria was used to decide which predictors were not confirmed yet. That has helped decide where there is need for further research, for example, 'Race', 'diet', 'exercise' and so on.

We also found the reporting of the evidence base for the predictors selected in the modelling studies suboptimal. Under-reporting has been mentioned by other observers before $^{9}$ and needs improving. The Transparent Reporting of a multivariable prediction model for Individual Prognosis or Diagnosis (TRIPOD) statement asks for all predictors used to be clearly defined. ${ }^{66}$ One way of improving this situation may be for TRIPOD checklist to encourage investigators to report the primary study of origin for every candidate predictor used in a model. Out of $35,10(29 \%)$ predictors were not supported by the existing evidence base applying PROGRESS standards and require further research.

There have been recent useful reviews and studies on ocular predictors and their natural history use as predictors of DR progression ${ }^{512} 1367$ Ocular signs identified in Optical coherence tomography and Fundus Fluorescein Angiography could also be potential predictors of DR progression. While the ocular signs recommended are suitable for prospective research studies, existing retrospective longitudinal data most commonly used for prognostic research are unlikely to have sufficient information on these predictors. There is an ever-increasing interest in fundus images-based detection, assisted by artificial intelligence. ${ }^{68}$ Prognostic factor research is a dynamic field and will benefit greatly with these newer technologies. Machine learning can handle the data from wider sources, can bring additional benefits from automation, unsupervised clustering of a much larger number of predictors and can also add new phenotypes associated with the outcomes. However, there are ethical, governance, interpretability issues and the process of development of these techniques are at an early stage of development and application. ${ }^{69}$ It is likely that future research will identify further potentially important predictors so an update may be required in the future.

\section{CONCLUSION}

We have been able to identify 19 evidence-based predictors for DR progression, using a novel method (NGT) and evidence review inline with PROGRESS recommendations. This smaller and more practical set provides a useful resource for a potential model to stratify patients for risk of DR progression, to aid clinical decision-making and optimise clinical care pathways. This set is ranked in importance by the NGT.

Acknowledgements The authors would like to thank four NHS trusts and their clinicians for their support and involvement in NGT. Also would like to express gratitude to Sophie Beese for kindly reviewing the manuscript for an internal peer review.

Contributors SH was responsible for concept and design of the work, for acquisition, analysis, interpretation of data and drafting the paper. Rest of the coauthors provided support in above, revised it critically and contributed in final draft.

Funding The authors have not declared a specific grant for this research from any funding agency in the public, commercial or not-for-profit sectors.

Competing interests None declared.

Patient consent for publication Not required.

Provenance and peer review Not commissioned; externally peer reviewed.

Data availability statement Data are available upon request.

Supplemental material This content has been supplied by the author(s). It has not been vetted by BMJ Publishing Group Limited (BMJ) and may not have been peer-reviewed. Any opinions or recommendations discussed are solely those of the author(s) and are not endorsed by BMJ. BMJ disclaims all liability and responsibility arising from any reliance placed on the content. Where the content includes any translated material, BMJ does not warrant the accuracy and reliability of the translations (including but not limited to local regulations, clinical guidelines, terminology, drug names and drug dosages), and is not responsible for any error and/or omissions arising from translation and adaptation or otherwise.

Open access This is an open access article distributed in accordance with the Creative Commons Attribution 4.0 Unported (CC BY 4.0) license, which permits others to copy, redistribute, remix, transform and build upon this work for any purpose, provided the original work is properly cited, a link to the licence is given, and indication of whether changes were made. See: https://creativecommons.org/ licenses/by/4.0/. 
ORCID iD

Sajjad Haider http://orcid.org/0000-0001-8111-8577

\section{REFERENCES}

1 Fong DS, Aiello L, Gardner TW, et al. Retinopathy in diabetes. Diabetes Care 2004;27(Suppl 1):S84-7.

2 Zhou B, Lu Y, Hajifathalian K, et al. Worldwide trends in diabetes since 1980: a pooled analysis of 751 population-based studies with 4.4 million participants. Lancet 2016;387:1513-30.

3 Mathur R, Bhaskaran K, Edwards E, et al. Population trends in the 10-year incidence and prevalence of diabetic retinopathy in the UK: a cohort study in the clinical practice research Datalink 2004-2014. BMJ Open 2017;7:e014444.

4 The Royal College of Ophthalmologists. The way forward agerelated macular degeneration and diabetic retinopathy 2016. Available: https://www.rcophth.ac.uk/wp-content/uploads/2015/ 10/RCOphth-The-Way-Forward-AMD-300117.pdf [Accessed $20 \mathrm{Jul}$ 2019].

5 Jyothi S, Elahi B, Srivastava A, et al. Compliance with the Quality Standards of national diabetic retinopathy screening Committee. Prim Care Diabetes 2009;3:67-72.

6 Scanlon PH, Aldington SJ, Leal J, et al. Development of a costeffectiveness model for optimisation of the screening interval in diabetic retinopathy screening. Health Technol Assess 2015;19:1-116.

7 Haider S, Sadiq SN, Moore D, et al. Prognostic prediction models for diabetic retinopathy progression: a systematic review. Eye 2019;33:702-13.

8 Offord DR, Kraemer HC. Risk factors and prevention. Evid Based Ment Health 2000;3:70-1.

9 Riley RD, Hayden JA, Steyerberg EW, et al. Prognosis research strategy (progress) 2: prognostic factor research. PLoS Med 2013;10:e1001380.

10 Steyerberg EW, Moons KGM, van der Windt DA, et al. Prognosis research strategy (progress) 3: prognostic model research. PLOS Med 2013;10:e1001381.

11 Hippisley-Cox J, Coupland C. Development and validation of risk prediction equations to estimate future risk of blindness and lower limb amputation in patients with diabetes: cohort study. BMJ 2015;351:h5441.

12 Sivaprasad S, Pearce E. The unmet need for better risk stratification of non-proliferative diabetic retinopathy. Diabet Med 2019;36:424-33

13 Jenkins AJ, Joglekar MV, Hardikar AA, et al. Biomarkers in diabetic retinopathy. Rev Diabet Stud 2015;12:159-95.

14 Lagani V, Chiarugi F, Thomson S, et al. Development and validation of risk assessment models for diabetes-related complications based on the DCCT/EDIC data. J Diabetes Complications 2015;29:479-87.

15 Sivo SA, Willson VL. Is parsimony always desirable? Identifying the correct model for a longitudinal panel data set. $J$ Experiment Educ 1998:66:249-55

16 Thangaratinam S, Ismail K, Sharp S, et al. Prioritisation of tests for the prediction of preeclampsia complications: a Delphi survey. Hypertens Pregnancy 2007;26:131-8.

17 Gallagher M, Hares T, Spencer J, et al. The nominal group technique: a research tool for general practice? Fam Pract 1993;10:76-81.

18 Hayden JA, van der Windt DA, Cartwright JL, et al. Assessing bias in studies of prognostic factors. Ann Intern Med 2013;158:280-6.

19 Poling R. Nominal group technique. University fo Arkansas, 2009.

20 Trusko B, Thorne $J$, Jabs $D$, et al. The standardization of uveitis Nomenclature (SUN) project. development of a clinical evidence base utilizing informatics tools and techniques. Methods Inf Med 2013;52:259-65. s1-6.

21 Angeles-Han ST, Lo MS, Henderson LA, et al. Childhood arthritis and rheumatology research alliance consensus treatment plans for juvenile idiopathic Arthritis-Associated and idiopathic chronic anterior uveitis. Arthritis Care Res 2019;71:482-91.

22 Avitabile T, Azzolini C, Bandello F, et al. Aflibercept in the treatment of diabetic macular edema: a review and consensus paper. Eur $J$ Ophthalmol 2017;27:627-39.

23 Douglas RS, Tsirbas A, Gordon M, et al. Development of criteria for evaluating clinical response in thyroid eye disease using a modified Delphi technique. Arch Ophthalmol 2009;127:1155-60.

24 Dreer LE, Girkin CA, Campbell L, et al. Glaucoma medication adherence among African Americans: program development. Optom Vis Sci 2013;90:883-97.

25 Ismail R, Azuara-Blanco A, Ramsay CR. Consensus on outcome measures for glaucoma effectiveness trials: results from a Delphi and nominal group technique approaches. J Glaucoma 2016;25:539-46.
26 Mosca M, Tani C, Aringer M, et al. European League against rheumatism recommendations for monitoring patients with systemic lupus erythematosus in clinical practice and in observational studies. Ann Rheum Dis 2010;69:1269-74.

27 Radomski MV, Finkelstein M, Llanos I, et al. Composition of a vision screen for servicemembers with traumatic brain injury: consensus using a modified nominal group technique. Am J Occup Ther 2014;68:422-9.

28 Suttle CM, Challinor KL, Thompson RE, et al. Attitudes and barriers to evidence-based practice in optometry educators. Optom Vis Sci 2015;92:514-23.

29 McMillan SS, King M, Tully MP. How to use the nominal group and Delphi techniques. Int J Clin Pharm 2016;38:655-62.

30 Fusch PI, Ness LR. Are we there yet? data saturation in qualitative research. The Qualitative Report 2015;20:1408-16.

31 Saunders B, Sim J, Kingstone T, et al. Saturation in qualitative research: exploring its conceptualization and operationalization. Qual Quant 2018:52:1893-907.

32 Palinkas LA, Horwitz SM, Green CA, et al. Purposeful sampling for qualitative data collection and analysis in mixed method implementation research. Adm Policy Ment Health 2015;42:533-44.

33 British Medical Association. Doctors' titles: explained, 2017. Available: file:///C:/Users/Admin/Downloads/PLG-doctors-titlesexplained\%20(1).pdf

34 Berger R. Now I see it, now I don't: researcher's position and reflexivity in qualitative research. Qualitative Res 2015;15:219-34.

35 Eleuteri A, Fisher AC, Broadbent DM, et al. Individualised variableinterval risk-based screening for sight-threatening diabetic retinopathy: the Liverpool risk calculation engine. Diabetologia 2017;60:2174-82.

36 Oake J, Aref-Eshghi E, Godwin M, et al. Using electronic medical record to identify patients with dyslipidemia in primary care settings: International classification of disease code matters from one region to a national database. Biomed Inform Insights 2017:9:1178222616685880.

37 Jeng C-J, Hsieh Y-T, Yang C-M, et al. Diabetic retinopathy in patients with diabetic nephropathy: development and progression. PLoS One 2016;11:e0161897.

38 Romero-Aroca P, Baget-Bernaldiz M, Navarro-Gil R, et al. Glomerula filtration rate and/or ratio of urine albumin to creatinine as markers for diabetic retinopathy: a ten-year follow-up study. J Diabetes Res 2018;2018:5637130.

39 Matthews DR, Stratton IM, Aldington SJ, et al. Risks of progression of retinopathy and vision loss related to tight blood pressure control in type 2 diabetes mellitus: UKPDS 69. Arch Ophthalmol 2004:122:1631-40.

40 Adler Al, Stratton IM, Neil HA, et al. Association of systolic blood pressure with macrovascular and microvascular complications of type 2 diabetes (UKPDS 36): prospective observational study. BMJ 2000;321:412-9.

41 Zhou Y, Zhang Y, Shi K, et al. Body mass index and risk of diabetic retinopathy: a meta-analysis and systematic review. Medicine 2017:96:e6754.

42 Tanaka S, Tanaka S, limuro S, et al. Predicting macro- and microvascular complications in type 2 diabetes: the Japan diabetes complications Study/the Japanese elderly diabetes intervention trial risk engine. Diabetes Care 2013;36:1193-9.

43 Stratton IM, Kohner EM, Aldington SJ, et al. UKPDS 50: risk factors for incidence and progression of retinopathy in type II diabetes over 6 years from diagnosis. Diabetologia 2001;44:156-63.

44 Klein R, Knudtson MD, Lee KE, et al. The Wisconsin epidemiologic study of diabetic retinopathy: XXII the twenty-five-year progression of retinopathy in persons with type 1 diabetes. Ophthalmology 2008;115:1859-68.

45 Early worsening of diabetic retinopathy in the diabetes control and complications trial. Arch Ophthalmol 1998;116:874-86. [Erratum appears in Arch Ophthalmol 1998 Nov;116(11):1469].

46 Klein BE, Moss SE, Klein R. Effect of pregnancy on progression of diabetic retinopathy. Diabetes Care 1990;13:34-40.

47 Forster AS, Forbes A, Dodhia $\mathrm{H}$, et al. Non-attendance at diabetic eye screening and risk of sight-threatening diabetic retinopathy: a population-based cohort study. Diabetologia 2013:56:2187-93.

48 KohnerEM, Stratton IM, Aldington SJ, et al. Relationship between the severity of retinopathy and progression to photocoagulation in patients with type 2 diabetes mellitus in the UKPDS (UKPDS 52). Diabet Med 2001;18:178-84.

49 Stratton IM, Adler Al, Neil HA, et al. Association of glycaemia with macrovascular and microvascular complications of type 2 diabetes (UKPDS 35): prospective observational study. BMJ 2000;321:405-12. 
50 Intensive blood-glucose control with sulphonylureas or insulin compared with conventional treatment and risk of complications in patients with type 2 diabetes (UKPDS 33). UK prospective diabetes study (UKPDS) group. Lancet 1998;352:837-53.

51 The effect of intensive diabetes treatment on the progression of diabetic retinopathy in insulin-dependent diabetes mellitus. The diabetes control and complications trial. Arch Ophthalmol 1995;113:36-51.

52 Diabetes Control and Complications Trial Research Group. Effect of pregnancy on microvascular complications in the diabetes control and complications trial. The diabetes control and complications trial Research Group. Diabetes Care 2000;23:1084-91.

53 Klein R, Lee KE, Gangnon RE, et al. The 25-year incidence of visual impairment in type 1 diabetes mellitus the Wisconsin epidemiologic study of diabetic retinopathy. Ophthalmology 2010;117:63-70.

54 Klein R. Hyperglycemie and microvascular and macrovascular disease in diabetes. Diabetes Care 1995;18:258-68.

55 Sjølie AK, Stephenson J, Aldington S, et al. Retinopathy and vision loss in insulin-dependent diabetes in Europe. The EURODIAB IDDM complications study. Ophthalmology 1997;104:252-60.

56 The ACCORD Study Group and ACCORD Eye Study Group. Effects of medical therapies on retinopathy progression in type 2 diabetes. N Engl J Med 2010;363:233-44. [Erratum appears in N Engl J Med. 2011 Jan 13;364(2):190], [Erratum appears in N Engl J Med. 2012 Dec 20;367(25):2458]

57 Soedamah-Muthu SS, Vergouwe Y, Costacou T, et al. Predicting major outcomes in type 1 diabetes: a model development and validation study. Diabetologia 2014;57:2304-14.

58 Kawasaki R, Tanaka S, Tanaka S, et al. Incidence and progression of diabetic retinopathy in Japanese adults with type 2 diabetes: 8 year follow-up study of the Japan diabetes complications study (JDCS). Diabetologia 2011;54:2288-94.

59 Lane M, Mathewson PA, Sharma HE, et al. Social deprivation as a risk factor for late presentation of proliferative diabetic retinopathy. Clin Ophthalmol 2015;9:347-52.

60 Stratton IM, Aldington SJ, Farmer AJ, et al. Personalised risk estimation for progression to sight-threatening diabetic retinopathy: how much does clinical information add to screening data? Diabetic Medicine 2014;31:23-4.

61 McEwan P, Bennett $\mathrm{H}$, Ward T, et al. Refitting of the UKPDS 68 risk equations to contemporary routine clinical practice data in the UK. Pharmacoeconomics 2015;33:149-61.

62 Klein R, Klein BE, Moss SE, et al. The Wisconsin epidemiologic study of diabetic retinopathy: XVII. The 14-year incidence and progression of diabetic retinopathy and associated risk factors in type 1 diabetes. Ophthalmology 1998;105:1801-15.

63 Harris Nwanyanwu K, Talwar N, Gardner TW, et al. Predicting development of proliferative diabetic retinopathy. Diabetes Care 2013;36:1562-8.

64 Sivaprasad S, Gupta B, Gulliford MC, et al. Ethnic variations in the prevalence of diabetic retinopathy in people with diabetes attending screening in the United Kingdom (DRIVE UK). PLoS One 2012;7:e32182.

65 Meltzer D, Egleston B. How patients with diabetes perceive their risk for major complications. Eff Clin Pract 2000;3:7-15

66 Moons KGM, Altman DG, Reitsma JB, et al. Transparent reporting of a multivariable prediction model for individual prognosis or diagnosis (TRIPOD): explanation and elaboration. Ann Intern Med 2015;162:W1-73.

67 Lee CS, Lee AY, Baughman D, et al. The United Kingdom diabetic retinopathy electronic medical record users group: report 3: baseline retinopathy and clinical features predict progression of diabetic retinopathy. Am J Ophthalmol 2017;180:64-71.
68 Gupta G, Kulasekaran S, Ram K, et al. Local characterization of neovascularization and identification of proliferative diabetic retinopathy in retinal fundus images. Comput Med Imaging Graph 2017:55:124-32.

69 Riley RD, van der Windt D, Croft P. Prognosis research in healthcare: concepts, methods and impact. OUP Oxford, 2019.

70 Mehlsen J, Erlandsen M, Poulsen PL, et al. Identification of independent risk factors for the development of diabetic retinopathy requiring treatment. Acta Ophthalmol 2011;89:515-21.

71 Grauslund J, Green A, Sjølie AK. Blindness in a 25-year follow-up of a population-based cohort of Danish type 1 diabetic patients. Ophthalmology 2009;116:2170-4.

72 Denniston AK, Lee AY, Lee CS, et al. United Kingdom diabetic retinopathy electronic medical record (UK DR EMR) users group: report 4, real-world data on the impact of deprivation on the presentation of diabetic eye disease at hospital services. $\mathrm{Br} \mathrm{J}$ Ophthalmol 2019;103:837-43.

73 Aspelund T, Thornórisdóttir O, Ólafsdottir E, et al. Individual risk assessment and information technology to optimise screening frequency for diabetic retinopathy. Diabetologia 2011;54:2525-32.

74 Yau JWY, Rogers SL, Kawasaki R, et al. Global prevalence and major risk factors of diabetic retinopathy. Diabetes Care 2012;35:556-64.

75 Hayes AJ, Leal J, Gray AM, et al. UKPDS outcomes model 2: a new version of a model to simulate lifetime health outcomes of patients with type 2 diabetes mellitus using data from the 30 year United Kingdom prospective diabetes study: UKPDS 82. Diabetologia 2013:56:1925-33.

76 Davis TM, Stratton IM, Fox CJ, et al. U.K. prospective diabetes study 22. Effect of age at diagnosis on diabetic tissue damage during the first 6 years of NIDDM. Diabetes Care 1997;20:1435-41.

77 Clarke PM, Gray AM, Briggs A, et al. A model to estimate the lifetime health outcomes of patients with type 2 diabetes: the United Kingdom prospective diabetes study (UKPDS) outcomes mode (UKPDS No. 68). Diabetologia 2004;47:1747-59.

78 Man REK, Sasongko MB, Wang JJ, et al. The association of estimated glomerular filtration rate with diabetic retinopathy and macular edema. Invest Ophthalmol Vis Sci 2015;56:4810-6.

79 Klein BE, Moss SE, Klein R, et al. The Wisconsin epidemiologic study of diabetic retinopathy. XIII. Relationship of serum cholesterol to retinopathy and hard exudate. Ophthalmology 1991;98:1261-5.

80 Shi R, Zhao L, Wang F, et al. Effects of lipid-lowering agents on diabetic retinopathy: a meta-analysis and systematic review. Int $J$ Ophthalmol 2018;11:287-95.

81 Klein R, Klein BE, Moss SE, et al. The Wisconsin epidemiologic study of diabetic retinopathy. IV. Diabetic macular edema. Ophthalmology 1984;91:1464-74.

82 Gupta A, Gupta V, Thapar S, et al. Lipid-lowering drug atorvastatin as an adjunct in the management of diabetic macular edema. $A m ~ J$ Ophthalmol 2004;137:675-82.

83 Ohkubo Y, Kishikawa H, Araki E, et al. Intensive insulin therapy prevents the progression of diabetic microvascular complications in Japanese patients with non-insulin-dependent diabetes mellitus: a randomized prospective 6-year study. Diabetes Res Clin Pract 1995;28:103-17.

84 Feldman-Billard S, Larger É, Massin P, et al. Early worsening of diabetic retinopathy after rapid improvement of blood glucose control in patients with diabetes. Diabetes Metab 2018;44:4-14

$85 \mathrm{~K}$ Muqit MM, Yang Y, Lipinski H, et al. Progression of preproliferative to proliferative diabetic retinopathy: a 3-year study in the Oxford population-based diabetic retinopathy screening programme. Diabet Med 2014;31:1018-9. 